\title{
Thermal Shock-Activated Spontaneous Growing of Nanosheets for Overall Water Splitting
}

Cite as

Nano-Micro Lett.

(2020) $12: 162$

Received: 28 May 2020

Accepted: 22 July 2020

Published online: 12 August 2020

(C) The Author(s) 2020

\author{
Han $\mathrm{Wu}^{1}$, Qi Lu${ }^{1}$, Jinfeng Zhang ${ }^{1}$, Jiajun Wang ${ }^{1}$, Xiaopeng Han ${ }^{1}$, Naiqin Zhao ${ }^{1}$, \\ Wenbin $\mathrm{Hu}^{1,2}$, Jiajun $\mathrm{Li}^{1}$, Yanan Chen ${ }^{1}{ }^{凶}$, Yida Deng ${ }^{1 凶}$ \\ $\triangle$ Yanan Chen, yananchen@tju.edu.cn; Yida Deng, yida.deng@tju.edu.cn \\ 1 School of Materials Science and Engineering, Tianjin Key Laboratory of Composite and Functional \\ Materials, Key Laboratory of Advanced Ceramics and Machining Technology, (Ministry of Education), \\ Tianjin University, Tianjin 300350, People's Republic of China \\ 2 Joint School of National University of Singapore and Tianjin University International Campus of Tianjin \\ University, Binhai New City, Fuzhou 350207, People's Republic of China
}

\section{HIGHLIGHTS}

- Nanomaterials-based nickel foam (NF-C/CoS/NiOOH) with nanosheets structure and core-shell heterostructure was prepared for the first time by a facile and fast synthesis strategy of Joule-heating and water soaking treatment.

- The formation mechanism of nanosheets structure was proposed that the driving force of nanosheets structure generation was the metastable nickel activated by thermal shock, and the $\mathrm{CoS}$ could induce the $\mathrm{NiOOH}$ nanosheets growing continually.

- $\mathrm{NF}-\mathrm{C} / \mathrm{CoS} / \mathrm{NiOOH}$ exhibited good oxygen evolution, hydrogen evolution, and overall water splitting performance.

\begin{abstract}
Nanomaterials based ' on nickel foam (NF) have been! widely applied in energy conver-' sion and storage field. Traditional ' synthesis methods such as hydrothermal method which is dangerous and high cost limited the scalable developments. Herein, we report a fast, simple, and low-cost synthesis method of nanomaterials based on ' NF by Joule-heating and water soak- '

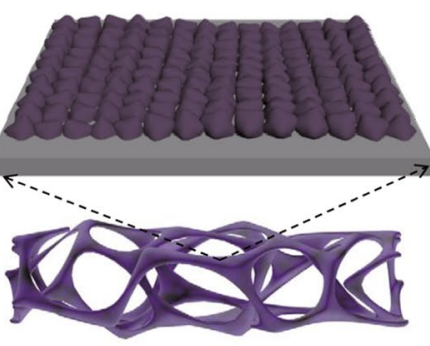

NF-precursor

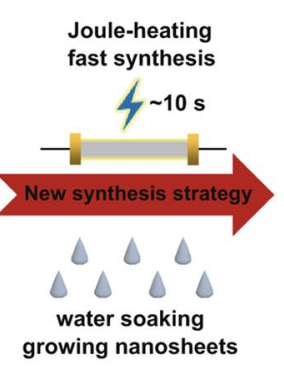

growing nanosheets ing treatment. Thin carbon-coated

$\mathrm{CoS}$ on NF (NF-C/CoS) was synthesized by Joule-heating for a few seconds with rapid cooling. And then, NF-C/CoS/NiOOH with core-shell heterostructure was fabricated by soaking treatment of NF-C/CoS in water on which NiOOH nanosheets grew spontaneously. The formation mechanism is proposed that the coordination complex precursor converts into C/CoS on NF driven by Joule-heating, and the nickel on the surface of NF is activated to form metastable nickel simultaneously. The metastable nickel reacting with water leads to the formation of $\mathrm{NiOOH}$, and the induction of $\mathrm{CoS}$ makes $\mathrm{NiOOH}$ grow continuously. This synthesis technology provides a new route to manufacture NF-based nanostructures, and the as-fabricated NF-C/CoS/NiOOH exhibits great potential as electrocatalyst for oxygen evolution reaction and hydrogen evolution reaction.
\end{abstract}

KEYWORDS Ultrafast synthesis; Spontaneous growing; Thermal shock; Seed inducing; Water splitting 


\section{Introduction}

Sustainable and green energy resources are becoming extremely important to meet the growing demand for energy developments due to the ever-rising environmental pollution and the increasing consumption of fossil fuels [1]. Recent studies on developing sustainable energy strategies to address the current environmental and energy challenges have attracted significant interests [2]. Electrocatalytic water splitting including hydrogen and oxygen producing is widely regarded as the most economical and effective way to produce clean and sustainable energy [3]. The overpotential corresponding to thermodynamics and kinetics of oxygen evolution reaction (OER) and hydrogen evolution reaction (HER) which are the half-reaction of water splitting depends on electrocatalytic materials [4].

Noble metal electrocatalysts such as $\mathrm{Pt}, \mathrm{Ru}$, and Ir have superior OER and HER electrocatalytic activities, but the development of noble metal electrocatalysts is restricted by the high-cost and conventional coating method in which the binder increases the resistance, buries the active sites, inhibits mass/electrons transports and the loading mass of the electrocatalysts is usually less than $1 \mathrm{mg} \mathrm{cm}^{-2}$, providing limited catalytically active sites [5, 6]. Enormous efforts have been dedicated to the development of effective non-noble electrocatalysts and self-supporting electrode [7]. Nanomaterials based on nickel foam (NF) as self-supporting electrocatalysts have been extensively studied because NF as a high conductive substrate has the porous structure to provide higher active area, and nickel has good electrocatalytic activity. The NF which is widely used in practical applications such as NiMH battery [8], fuel cells [9], and electrocatalysts [10,11] is low-cost and mature in industrial production. Studies in recent years have shown that NF-based nanoarchitectures as electrocatalysts are mainly prepared by hydrothermal or solvothermal methods because nickel has high reactivity with other additives to form kinds of nanostructures such as nanosheets and nanorods in water or other organic solvents under high temperature and pressure [12, 13]. However, hydrothermal and solvothermal processing requires high temperature and high pressure lasting a long time, which are harsh and dangerous conditions during industrial manufacturing. The use of additives and organic solvents increases the cost and may be harmful to the environment.
These are not conducive to the industrial production of electrocatalysts based on NF. Therefore, it is necessary to find a fast and low-cost method to manufacture NFbased electrocatalysts. In 2016, Chen et al. for the first time reported nanoparticles synthesized by simple Jouleheating and rapid quenching, which provide a new method of ultrafast nanomanufacturing [14]. In the next few years, Yao et al. prepared high-entropy-alloy nanoparticles and single atoms loaded carbon nanofibers for small molecule electrocatalysis in the same method $[15,16]$. Chen et al. prepared $\mathrm{FeS}_{2}$ nanoparticles on reduced graphene oxides from $\mathrm{FeS}_{2}$ microparticles in the same method [17]. This method which is essentially a thermal synthesis processing has superfast synthesis speed, but it still has limitations such as too high synthesis temperature and over-reliance on carbon supports.

Here, we designed and fabricated an integrated electrocatalyst (NF-C/CoS/NiOOH) by using NF as Joule-heating substrate and water soaking treatment innovatively. The cobalt-thiourea coordination complex as precursor loading on NF in situ transforms into doped carbon-coated $\mathrm{CoS}$ (NF-C/CoS) by Joule-heating with raped cooling which leads to nickel activated to be metastable that is like the "seeds" forming magically and the "soil" becoming fertile through lightning (Fig. 1a, b). It is remarkable that NF-C/ $\mathrm{CoS} / \mathrm{NiOOH}$ with nanosheet structure was fabricated by simple soaking treatment of NF-C/CoS in water on which a nanostructure formation mechanism was proposed for the first time (Fig. 1b). The metastable nickel reacting with water led to the formation of $\mathrm{NiOOH}$ nanosheets and the $\mathrm{C} / \mathrm{CoS}$ like "seeds" in the "flowerpot" induced flowerlike $\mathrm{NiOOH}$ nanosheets growing spontaneously and continuously (Fig. 1a). NF-C/CoS/NiOOH exhibited good OER, HER, and overall water splitting electrocatalytic performance.

\section{Experimental Section}

\subsection{Materials Preparation}

\subsubsection{Chemicals}

Cobalt (II) acetate tetrahydrate, thiourea, $\mathrm{Pt} / \mathrm{C}$ (wt \% $=20 \%$ ), and $\mathrm{IrO}_{2}$ were purchased from Aladdin (Shanghai, China). Nickel foam (NF) without any treatment was cut to $3.5 \mathrm{~cm} \times 0.5 \mathrm{~cm} \times 0.1 \mathrm{~cm}$. 


\subsubsection{Preparation of NF-C/CoS/NiOOH}

Cobalt (II) acetate tetrahydrate and thiourea were dissolved into ethanol to prepare $1 \mathrm{M}$ cobalt-thiourea coordination complex solution. The solution was dropped into the NF with $100 \mu \mathrm{L} \mathrm{cm}^{-2}$ and then the NF dried at $60{ }^{\circ} \mathrm{C}$ for $30 \mathrm{~min}$. The direct current supply was adopted for Joule-heating (MAISHENG-MP1203D, 0-50 A, 0-50 V). The as-prepared cobalt-thiourea coordination complex solution was dropped into the nickel foam as shown in Fig. R3. The distance between powered clamps was $2.5 \mathrm{~cm}$. The cobalt-thiourea coordination complex loading nickel foam clamped on the power clamps was transferred into the argon glove box. The clamp was passed to a current of 5A for 10-15 s, when the nickel foam changes from purple to black (Fig. S1b, c). Finally, the NF-C/CoS/NiOOH was prepared by soaking $\mathrm{NF}-\mathrm{C} / \mathrm{CoS}$ in water overnight.

\subsubsection{Preparation of $\mathrm{NF}-\mathrm{C} / \mathrm{Ni}(\mathrm{OH}) \mathrm{S}$}

Thiourea was dissolved into ethanol to prepare $1 \mathrm{M}$ solution. The solution was dropped into the NF with $100 \mu \mathrm{L} \mathrm{cm}^{-2}$ and then the NF dried at $60{ }^{\circ} \mathrm{C}$ for $30 \mathrm{~min}$. The NF clamped on the power clamps was passed a current of $5 \mathrm{~A}$ in the argon glove box for about $10 \mathrm{~s}$ and then soaking in water overnight.

\subsubsection{Preparation of Comparative Samples}

In order to prove the formation processing of NF-C/CoS/ $\mathrm{NiOOH}$, a series of comparative samples were prepared. The sample NF-5A was prepared by same as NF-C/CoS/NiOOH without the dropping of the cobalt-thiourea coordination complex solution. The sample NF-C/CoS/NiOOH-5 min was prepared by only changing the soaking time to $5 \mathrm{~min}$. The

(a)

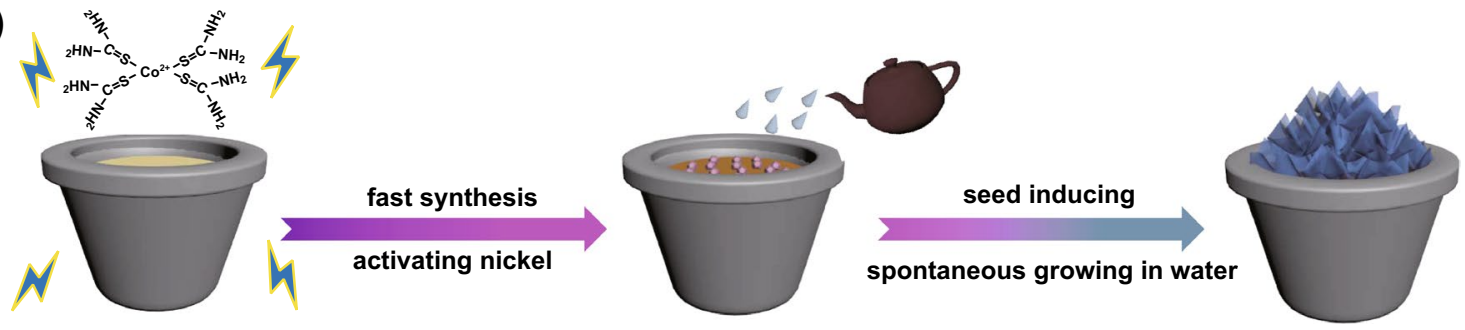

(b) NF-precursor

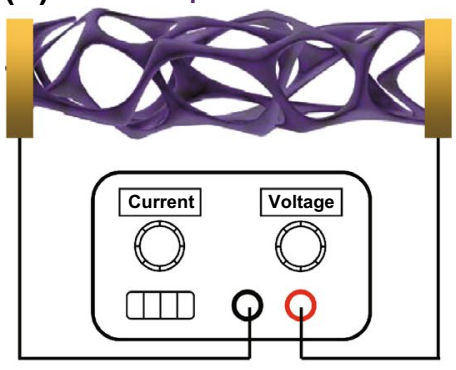

Ar atmosphere

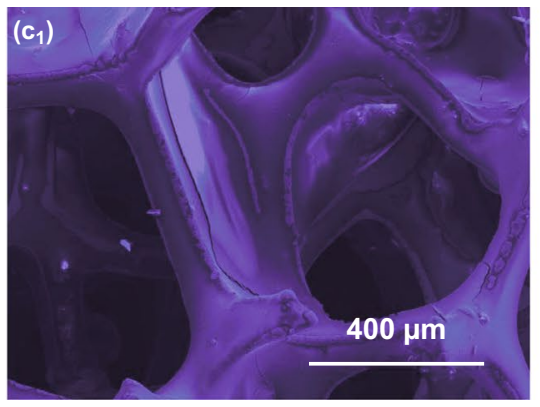

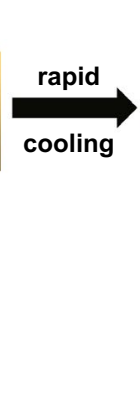
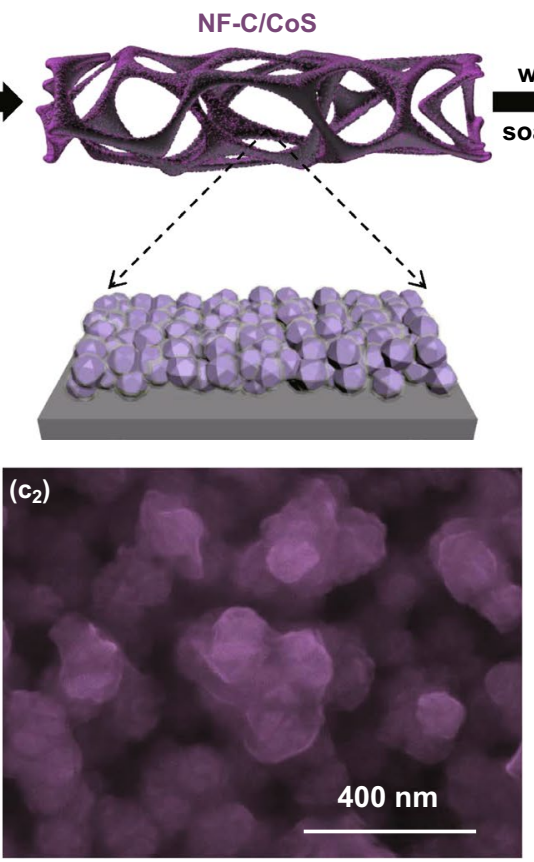
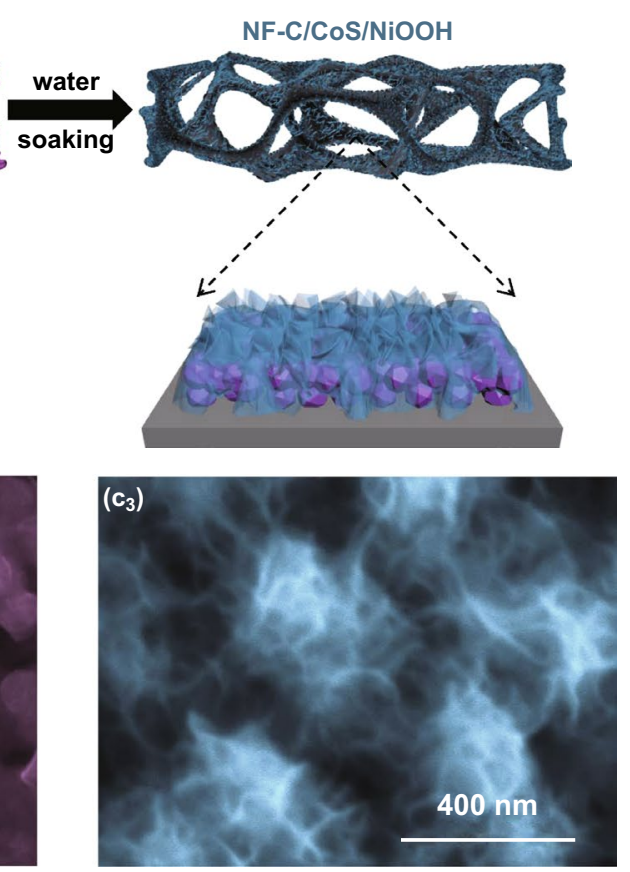

Fig. 1 a Synthesis strategy of NF-C/CoS/NiOOH. b Schematic illustration for preparation of NF-C/CoS/NiOOH. SEM of $\mathbf{c}_{\mathbf{1}} \mathrm{NF}-\mathrm{precursor}$, $\mathbf{c}_{\mathbf{2}}$ $\mathrm{NF}-\mathrm{C} / \mathrm{CoS}$ and $\mathbf{c}_{\mathbf{3}} \mathrm{NF}-\mathrm{NF}-\mathrm{C} / \mathrm{CoS} / \mathrm{NiOOH}$ 
sample NF-cobalt oxide was prepared by same as NF-C/ $\mathrm{CoS} / \mathrm{NiOOH}$ with only cobalt-ethanol solution. The samples named NF-C/CoS/NiOOH-3A, NF-C/CoS/NiOOH-7A, $\mathrm{NF}-\mathrm{C} / \mathrm{CoS} / \mathrm{NiOOH}-10 \mathrm{~A}$ were prepared by only changing the current from 5 to 3,7 , and $10 \mathrm{~A}$ without other changes in the synthesis of NF-C/CoS/NiOOH.

\subsection{Materials Characterization}

The microstructure, energy-dispersive X-ray spectroscopy (EDS), and element distribution mapping were characterized by scanning electron microscopy (SEM, JSM-7800F), transmission electron microscopy (TEM, JEOL-2100F). Raman spectra were measured using Edinburgh RM5 with the excitation laser line at $532 \mathrm{~nm}$. Light microscopy images were characterized by using SOPTOP-BH200m. $\mathrm{X}$-ray photoelectron spectra test was performed on a scientific ESCALAB 250 instrument. The temperature evolution during the synthesis of NF-C/CoS was performed using an ImageIR8355BB high-speed thermal imaging camera.

\subsection{Electrochemical Measurement}

Electrochemical measurements were taken in a threeelectrode system on an electrochemical workstation $(\mathrm{CH}$ Instruments $660 \mathrm{E}$ ) at room temperature in $1 \mathrm{M} \mathrm{KOH}$ solution. NF-C/CoS/NiOOH, NF-C/CoS and NF $\left(0.5 \times 2 \mathrm{~cm}^{2}\right)$ were used directly as the working electrode. A graphite rod was used as the counter electrode and saturated calomel electrode (SCE) was used as the reference electrode. $10 \mathrm{mg}$ $\mathrm{IrO}_{2}$ and $10 \mathrm{mg} \mathrm{Pt} / \mathrm{C}$ were dispersed, respectively, into 965 $\mu \mathrm{L}$ isopropyl alcohol and $35 \mu \mathrm{L}$ Nafion solution (5\%) with 30 min sonication. NF-Pt/C and $\mathrm{NF}-\mathrm{IrO}_{2}$ were prepared by loading powder ink ( $200 \mu \mathrm{L})$ onto NF. Alkaline overall water splitting measurement was taken in a two-electrode system by using bifunctional NF-C/CoS/NiOOH as both anode and cathode in $1 \mathrm{M} \mathrm{KOH}$. The measured potentials were normalized to reversible hydrogen electrode (RHE) based on the Nernst equation:

$E(\mathrm{RHE})=E(\mathrm{SCE})+0.059 \times \mathrm{pH}+0.24$.

All the polarization curves were tested at a scan rate of $5 \mathrm{mV} \mathrm{s}^{-1}$. All the polarization curves and chronopotentiometry curves were corrected for iR losses. Electrochemical impedance spectroscopy (EIS) were measured in a frequency from $10^{5}$ to $0.01 \mathrm{~Hz}$ at $1.526 \mathrm{~V}$ (OER) vs RHE, $-0.173 \mathrm{~V}$ (HER) vs RHE and $1.72 \mathrm{~V}$ (overall water splitting). The Faraday efficiency of OER and HER on NF-C/CoS/NiOOH was tested and analyzed by using gas chromatograph (GC) with gas-tight H-cell. Employ a GC, equipped with a combination of molecular sieve $5 \mathrm{~A}(2 \mathrm{~m} \times 4 \mathrm{~mm})$, Porapak- $\mathrm{N}(2 \mathrm{~m} \times 4 \mathrm{~mm})$, and Porapak- $\mathrm{N}(3 \mathrm{~m} \times 4 \mathrm{~mm})$, for $\mathrm{O}_{2}$ and $\mathrm{H}_{2}$ gas products analysis during OER and HER test. A thermal conductivity detector was used to quantify $\mathrm{H}_{2}$ and $\mathrm{O}_{2}$ concentration. Chronopotentiometry curves were tested at 10,20, and $50 \mathrm{~mA} \mathrm{~cm}{ }^{-2}$ for 10,5 , and $2 \mathrm{~min}$, respectively. The gas was collected with syringe with good sealing performance for testing in GC. The calculation of Faraday efficiency is the ratio of actual gas production to theoretical gas production.

\section{Results and Discussion}

\subsection{Morphology and Structure Characterization}

The cobalt-thiourea coordination complex on NF exhibited the color of purple and became black after power-up (Fig. $\mathrm{S} 1$ ). The evolution curve of the highest temperature on NF during the synthesis processing of NF-C/CoS indicates that the highest temperature of Joule-heating was about $450{ }^{\circ} \mathrm{C}$ and the cooling rate was about $100{ }^{\circ} \mathrm{C} \mathrm{s}^{-1}$ (Fig. S2). The scanning electron microscopy (SEM) and optical micrographs of the cobalt-thiourea coordination complex on NF indicated evenly distributed on NF which was beneficial to the uniform formation of $\mathrm{C} / \mathrm{CoS}$ (Figs. 1 $\mathrm{c}_{1}$ and S3).

The SEM images of NF-C/CoS showed that carbon-coated $\mathrm{CoS}$ nanoparticles grew on the surface of NF (Figs. $1 \mathrm{c}_{2}$ and $\mathrm{S} 4 \mathrm{a}, \mathrm{b})$. And then the microstructure of NF-C/CoS/NiOOH transforms to hierarchical nanosheets on the surface of $\mathrm{C} /$ $\mathrm{CoS}$ nanoparticles after soaking treatment of NF-C/CoS in water (Figs. $1 \mathrm{c}_{3}$ and $\mathrm{S} 4 \mathrm{c}, \mathrm{d}$ ). The energy-dispersive X-ray spectroscopy (EDS) demonstrated that both NF-C/CoS and $\mathrm{NF}-\mathrm{C} / \mathrm{CoS} / \mathrm{NiOOH}$ had $\mathrm{C}, \mathrm{N}, \mathrm{O}, \mathrm{S}, \mathrm{Co}, \mathrm{Ni}$, and the ratio of Co and $\mathrm{S}$ was almost 1: 1 (Fig. S5a, b). Besides, NF-C/ $\mathrm{CoS} / \mathrm{NiOOH}$ showed a sharp increase in oxygen content compared with NF-C/CoS demonstrating the formation of $\mathrm{NiOOH}$ by water soaking treatment. The microstructure of 
$\mathrm{C} / \mathrm{CoS}$ was irregular particles proved by transmission electron microscopy (TEM) image in Fig. 2a. The high-resolution transmission electron microscopy (HRTEM) image showed crystalline CoS with about $2 \mathrm{~nm}$ carbon layer on the surface of CoS marked by red line and the FFT inverse image showed (101) plane of CoS with lattice distance of $0.255 \mathrm{~nm}$ (Fig. 2b). Also, the selected area electron diffraction (SAED) pattern proved that the phase of the irregular particles was crystalline $\mathrm{CoS}$ with four obvious diffraction rings corresponding to (100), (101), (102), and (110) of CoS, respectively (Fig. 2f) [18]. The elemental mapping showed that the particles were mainly composed of $\mathrm{Co}$ and $\mathrm{S}$ as well as a small amount of C, N, O (Fig. 2g). The microstructure of C/ $\mathrm{CoS} / \mathrm{NiOOH}$ was core-shell heterostructure with $\mathrm{CoS}$ nanoparticles as the core and $\mathrm{C} / \mathrm{NiOOH}$ hierarchical nanosheets as the shell (Fig. 2c, d). The SAED patterns indicated that the main crystalline phase of $\mathrm{C} / \mathrm{CoS} / \mathrm{NiOOH}$ was still $\mathrm{CoS}$, and the crystalline phase of nanosheets was $\mathrm{NiOOH}$ with low crystallinity corresponding to four diffraction rings with (101), (210), (310), and (202) of $\mathrm{NiOOH}$, respectively (Fig. 2f). The HRTEM image showed that the nanosheets contained the amorphous area and the crystalline area which was NiOOH proved by FFT inverse image (Fig. 2e). The elemental mappings indicated that the irregular particles were still $\mathrm{CoS}$ and hierarchical nanosheets coated on the $\mathrm{CoS}$ included $\mathrm{C}, \mathrm{N}, \mathrm{O}$, and $\mathrm{Ni}$ in which the signal of $\mathrm{Ni}$ and $\mathrm{O}$ was strong (Fig. 2h). Moreover, the nanosheets were mainly composed of $\mathrm{Ni}, \mathrm{O}$ and a small amount of $\mathrm{C}, \mathrm{N}$, $\mathrm{Co}, \mathrm{S}$ demonstrating the formation of $\mathrm{NiOOH}$ with doped Co and N-, O-, S-doped carbon (Fig. S6). The samples of $\mathrm{NF}-\mathrm{C} / \mathrm{CoS}$ and NF-C/CoS/NiOOH showed complex element composition and structure so that we take the main structure of each part to name in order to simplify the naming of samples. In general, the structure of NF-C/CoS was thin carbon-coated CoS nanoparticles and the structure of NF-C/ $\mathrm{CoS} / \mathrm{NiOOH}$ was $\mathrm{C} / \mathrm{NiOOH}$ nanosheets on the surface of CoS nanoparticles.

The Raman spectra only showed the signal of $\mathrm{CoS}$ on $\mathrm{NF}-\mathrm{C} / \mathrm{CoS}$ and NF-C/CoS/NiOOH indicating that the phase of $\mathrm{CoS}$ remained stable after soaking treatment in water, and a small amount as well as low crystalline of $\mathrm{C}$ and $\mathrm{NiOOH}$ (Fig. 3a) [19]. The existence of C, N, O, S, $\mathrm{Co}$, and $\mathrm{Ni}$ on NF-C/CoS and NF-C/CoS/NiOOH could also be proved by the X-ray photoelectron spectroscopy (XPS) survey spectra in Fig. 3b. Moreover, the signal strength of $\mathrm{O}$ on NF-C/CoS/NiOOH increased compared to $\mathrm{NF}-\mathrm{C} / \mathrm{CoS}$ demonstrating the increase in $\mathrm{O}$ after soaking treatment in water. The high-resolution $\mathrm{C} 1 \mathrm{~s}$ spectrum of NF-C/CoS and NF-C/CoS/NiOOH could be deconvoluted into four individual component peaks corresponding to $\mathrm{C}=\mathrm{C} / \mathrm{C}-\mathrm{C}(284.6 \mathrm{eV}), \mathrm{C}-\mathrm{N} / \mathrm{C}-\mathrm{S}(285.1 \mathrm{eV}), \mathrm{C}-\mathrm{O}$ $(286.9 \mathrm{eV})$, and $\mathrm{O}=\mathrm{C}-\mathrm{O}(288.3 \mathrm{eV})$ showing the $\mathrm{N}-, \mathrm{S}-$, O-doped carbon (Fig. 3c) [20]. The high-resolution N $1 \mathrm{~s}$ spectrum of NF-C/CoS and NF-C/CoS/NiOOH could be proved the formation of pyridinic $\mathrm{N}(398.9 \mathrm{eV})$ and pyrrolic $\mathrm{N}(400.0 \mathrm{eV})$, as shown in Fig. 3d [21]. The highresolution $\mathrm{O} 1 \mathrm{~s}$ spectrum could be deconvoluted into three peaks for NF-C/CoS corresponding to $\mathrm{C}=\mathrm{O}(531.8 \mathrm{eV})$, $\mathrm{C}-\mathrm{O} /-\mathrm{OH}(531.2 \mathrm{eV})$, and $\mathrm{Co}-\mathrm{O}(529.7 \mathrm{eV})$, but no signal of $\mathrm{Co}-\mathrm{O}$ could be found in NF-C/CoS/NiOOH (Fig. 3e). The signal strength of $\mathrm{C}-\mathrm{O} /-\mathrm{OH}$ increased showing the formation of $\mathrm{NiOOH}$ with $-\mathrm{OH}$ [22]. In addition, the signal of Co-O disappeared after soaking treatment in water which was proposed that $\mathrm{Co}-\mathrm{O}$ came from the bonding of cobalt on the surface of $\mathrm{CoS}$ and $\mathrm{O}$ on the carbon, and the formation of $\mathrm{NiOOH}$ led to the disappearance of $\mathrm{Co}-\mathrm{O}$. The high-resolution spectrum of $\mathrm{S} 2 \mathrm{p}$ clearly reflected that both NF-C/CoS and NF-C/CoS/NiOOH had Co-S and $\mathrm{C}-\mathrm{S}-\mathrm{C}$ corresponding to $\mathrm{CoS}$ - and $\mathrm{S}$-doped carbon (Fig. 3f) [23]. Importantly, NF-C/CoS/NiOOH showed signal peaks of $\mathrm{SO}_{\mathrm{x}}$ because of the bonding of $\mathrm{S}$ in $\mathrm{CoS}$ and $\mathrm{O}$ in $\mathrm{H}_{2} \mathrm{O}$. The high-resolution spectrum of Co $2 \mathrm{p}$ clearly reflected that both NF-C/CoS had $\mathrm{Co}^{2+}$ as well as $\mathrm{Co}^{0}$ and $\mathrm{NF}-\mathrm{C} / \mathrm{CoS} / \mathrm{NiOOH}$ only had $\mathrm{Co}^{2+}$ that $\mathrm{Co}^{2+}$ came from $\mathrm{CoS}$ mainly and Co between the surface of $\mathrm{CoS}$ and carbon showed $\mathrm{Co}^{0}$ due to the reduction of carbon (Fig. 3g) [24]. The high-resolution spectrum of Ni $2 p$ clearly reflected that NF-C/CoS had the signal peaks of $\mathrm{Ni}^{0}, \mathrm{Ni}^{2+}$, and $\mathrm{Ni}^{3+}$ that $\mathrm{Ni}^{0}$ came from $\mathrm{NF}$ and $\mathrm{Ni}^{2+}$ as well as $\mathrm{Ni}^{3+}$ could come from doped $\mathrm{Ni}$ in $\mathrm{CoS}$ (Fig. 3h) [25, 26]. And then $\mathrm{NF}-\mathrm{C} / \mathrm{CoS} / \mathrm{NiOOH}$ had the signal of $\mathrm{Ni}^{0}$ and $\mathrm{Ni}^{3+}$ corresponding to $\mathrm{NF}$ and $\mathrm{NiOOH}$, respectively.

\subsection{Analysis of Formation Mechanism}

It was an interesting phenomenon that $\mathrm{NiOOH}$ nanosheets grew spontaneously by soaking treatment in water compared with other synthesis methods of nanosheets on NF such as hydrothermal method and electrodeposition method. Here, we made a simple analysis and speculation on the growing mechanism of NF-C/CoS/NiOOH. As 

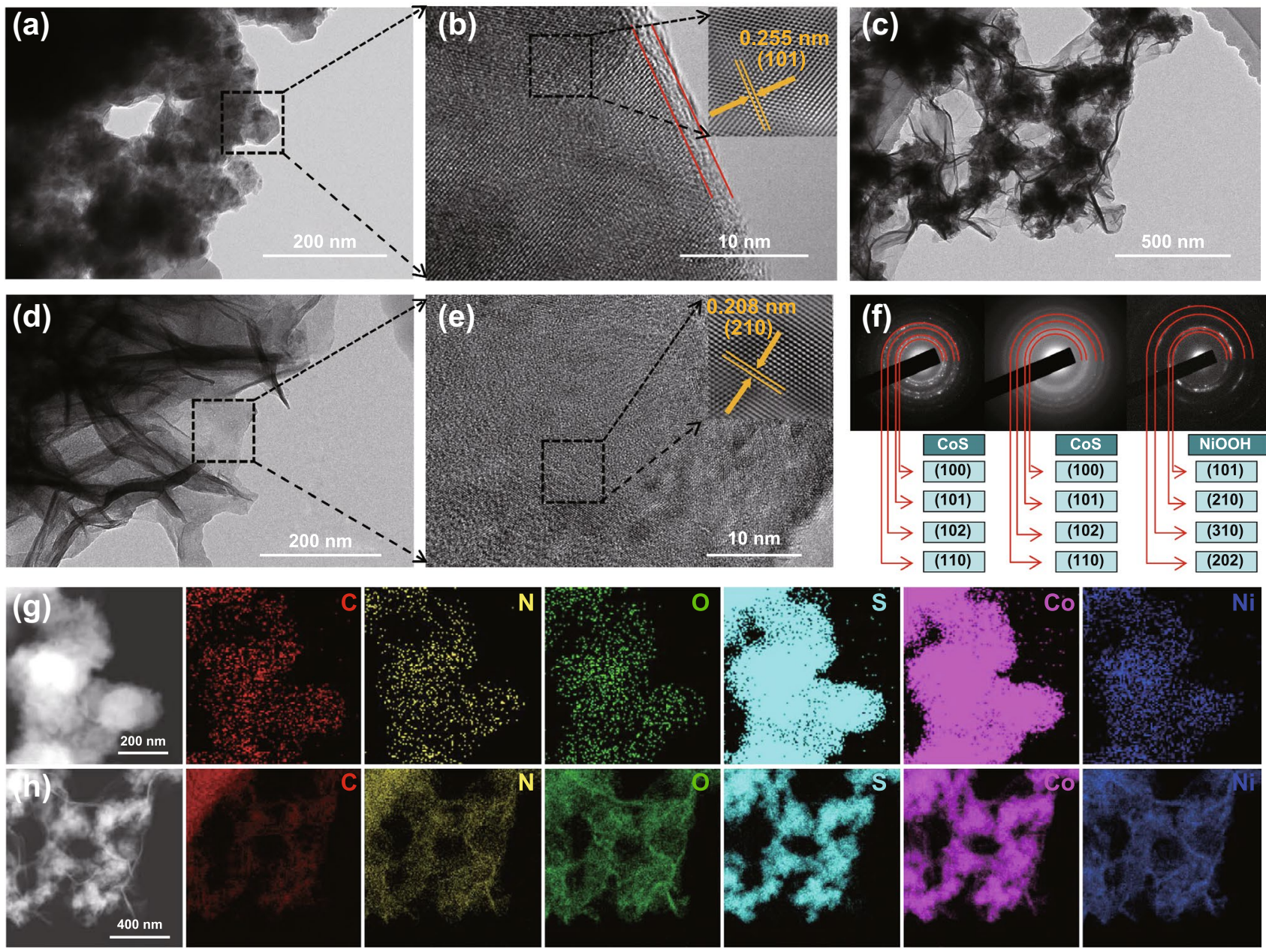

Fig. 2 a TEM of NF-C/CoS. b HRTEM of NF-C/CoS (inset: FFT inverse pattern). c-d SEM of NF-C/CoS/NiOOH. e HRTEM of NF-C/CoS/ $\mathrm{NiOOH}$ (inset: FFT inverse pattern). f SAED patterns of Fig. $2 \mathbf{a}, \mathbf{c}$, and $\mathbf{d}$, respectively. $\mathbf{g}$ HADDF image and elemental mapping of NF-C/CoS. h HADDF image and elemental mapping of NF-C/CoS/NiOOH

shown in Fig. 4, the cobalt-thiourea coordination complex on NF converted to doped carbon-coated CoS by Jouleheating that $\mathrm{N}-$, O-, S-doped carbon came from thiourea and $\mathrm{CH}_{3} \mathrm{COO}-$. Meanwhile, nickel on the surface of NF was activated to form metastable nickel by cobalt-thiourea coordination complex and Joule-heating. Figure S7 demonstrates that there was no formation of nanosheets on NF-5A indicating that bare NF by only Joule-heating was not activated indicating the necessity of cobalt-thiourea coordination complex for the spontaneous growing of $\mathrm{NiOOH}$ nanosheets. When only cobalt acetate solution was added into NF, the as-prepared sample NF-cobalt oxide showed a little cobalt oxide on NF indicating that the activation of nickel was mainly caused by thiourea (Fig. S8). In fact, the $\mathrm{S}^{2-}$ of $\mathrm{CoS}$ had strong reducibility and instability in water so that $\mathrm{S}$ on the surface of $\mathrm{CoS}$ could bond with $\mathrm{O}$ in water proved in Fig. 3f. In addition, the metastable nickel on the surface of NF reacted with water led to the formation of $\mathrm{NiOOH}$. Moreover, the $\mathrm{O}$ which came from water on the surface of $\mathrm{CoS}$ became the anchors of $\mathrm{NiOOH}$ sustained growing to led to the final formation of $\mathrm{C} / \mathrm{NiOOH}$ coated on the surface of CoS. Figure S9 shows that the nanosheets of NF-C/CoS/NiOOH-5 min had formed indicating the instantaneity of $\mathrm{NiOOH}$ formation. Furthermore, Fig. S10a shows that the crystalline CoS would not form when the current is not high enough ( $3 \mathrm{~A})$, but it could activate the NF to a certain extent, resulting in a small number of nanosheets. Figure S10b, c demonstrates that NF-C/CoS/NiOOH could be also prepared when the currents were 7 and $10 \mathrm{~A}$ higher than $5 \mathrm{~A}$, but the NF would 


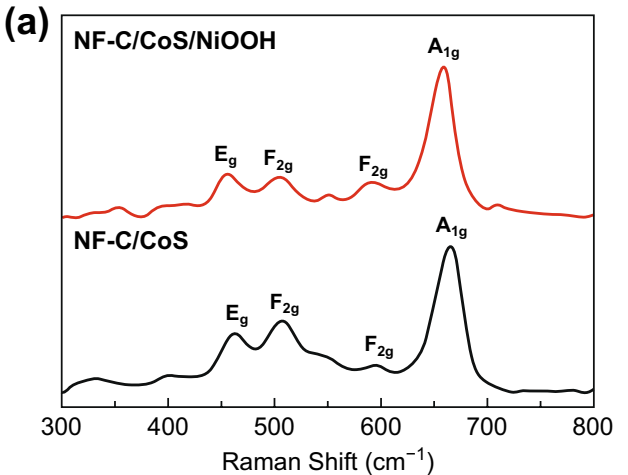

(c)

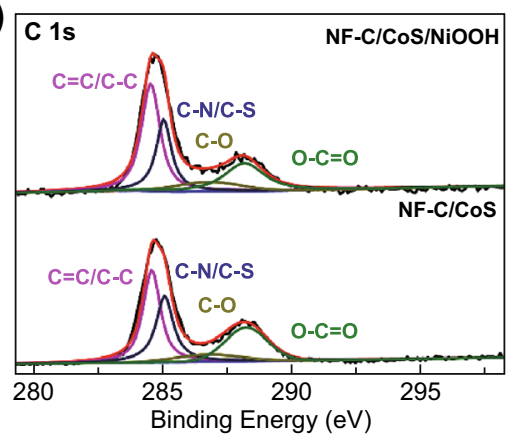

(f)

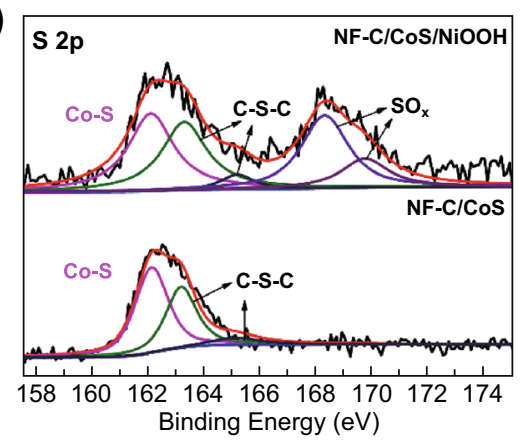

(d)

(g) (b)
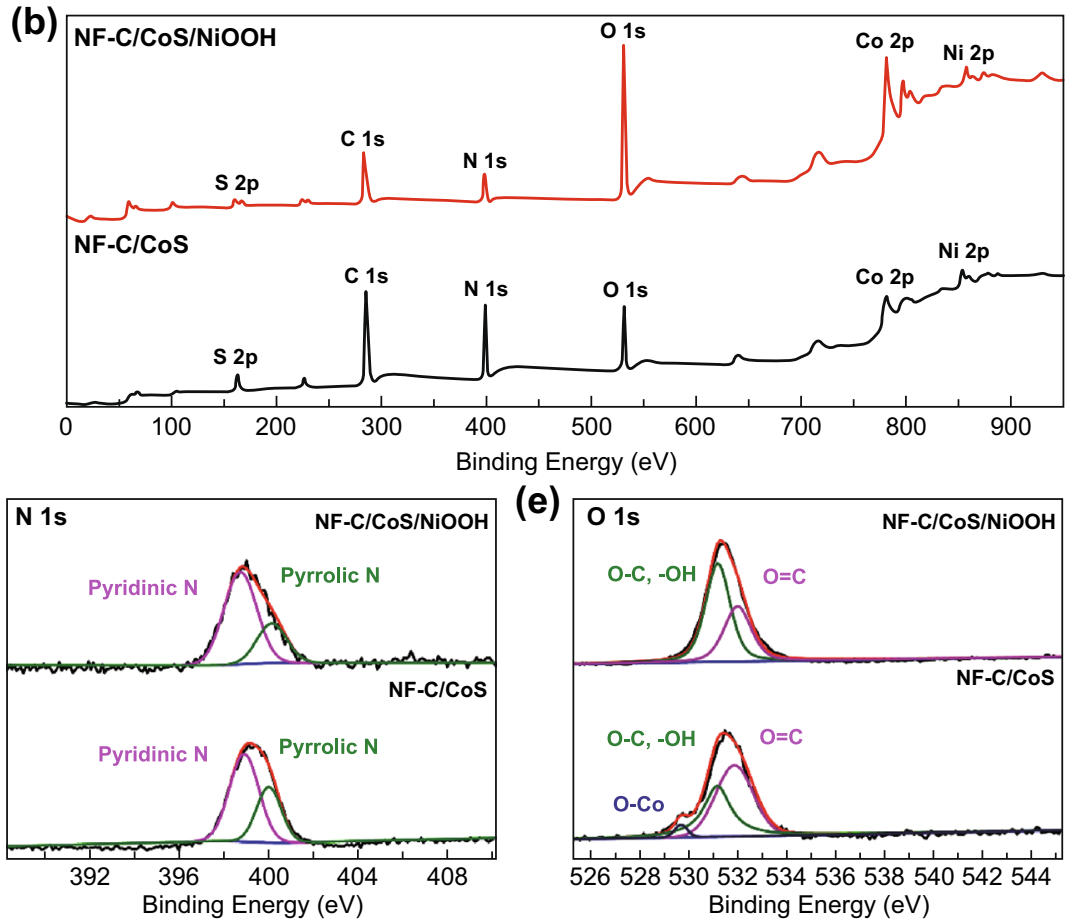

(e)
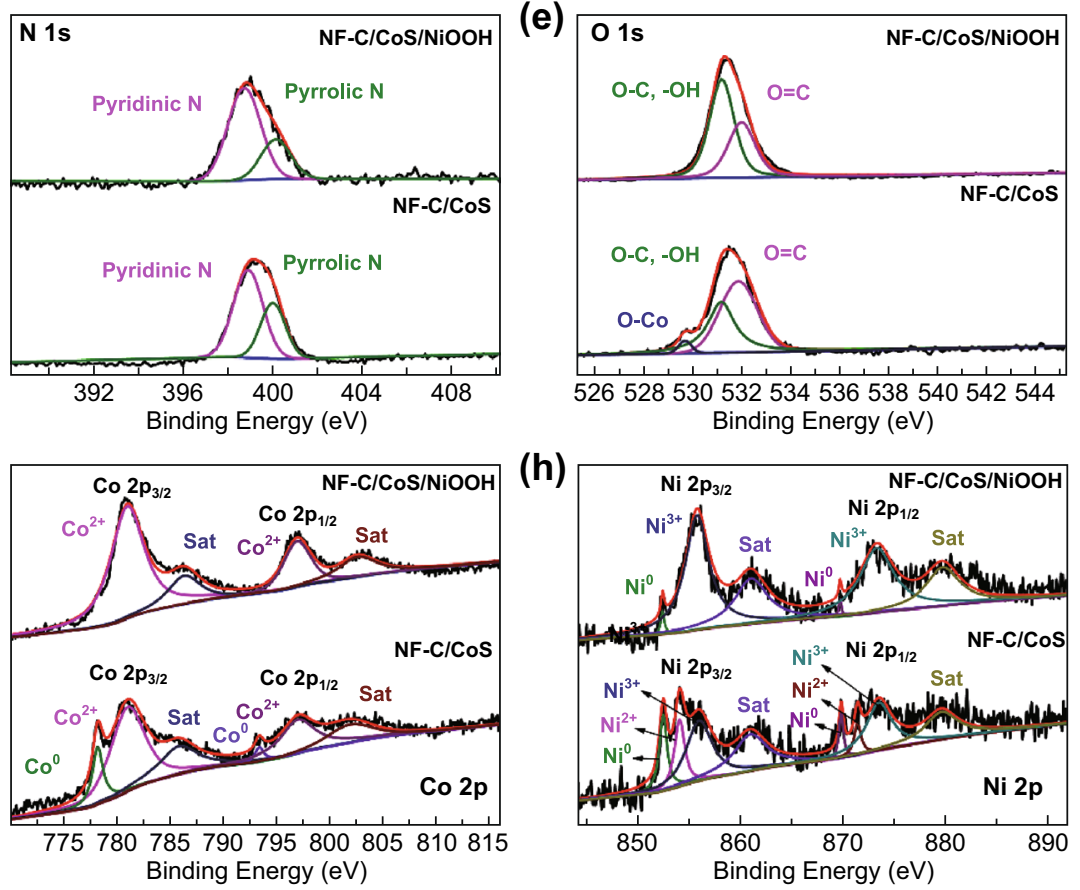

(h)

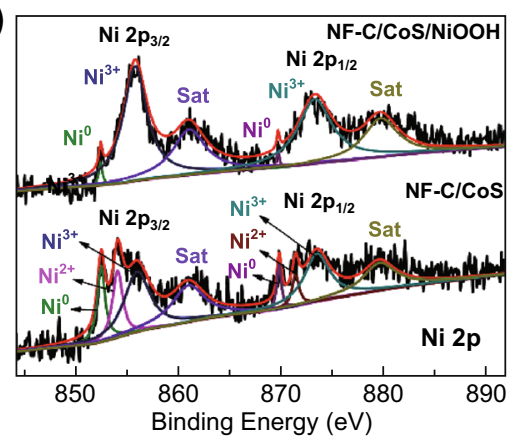

Fig. 3 a Raman spectrum of NF-C/CoS and NF-C/CoS/NiOOH. b XPS survey spectra of NF-C/CoS and NF-C/CoS/NiOOH. c C 1 s, d N 1 s, e $\mathrm{O} 1 \mathrm{~s}, \mathbf{f} \mathrm{S} 2 \mathrm{p}, \mathbf{g} \mathrm{Co} 2 \mathrm{p}, \mathbf{h}$ Ni 2p of NF-C/CoS and NF-C/CoS/NiOOH

be too brittle to used practically when the current was too high. According to the above data analysis, in general, the driving force of nanosheets structure generation was the activated metastable nickel, metastable nickel reacted with $\mathrm{H}_{2} \mathrm{O}$ to form $\mathrm{NiOOH}$ nanosheets, and sulfur-oxygen bonding on the surface of $\mathrm{CoS}$ could induce the $\mathrm{NiOOH}$ nanosheets growing continually.

\subsection{Electrocatalytic Performances}

We proved that the activation of nickel was due to the instantaneous thermal effect of Joule-heating and the cobalt-thiourea coordination complex in which thiourea plays an important role. Therefore, we also prepared NF-C/ $\mathrm{Ni}(\mathrm{OH}) \mathrm{S}$ with nanosheets structure by the same Joule-heating synthesis and soaking treatment in water for thiourea on NF. There were some similarities in the formation, morphology, and structure for NF-C/CoS/NiOOH and NF-C/ $\mathrm{Ni}(\mathrm{OH}) \mathrm{S}$. It could be proved that the carbon was N-, O-, $\mathrm{S}$-doped carbon and the amorphous $\mathrm{Ni}(\mathrm{OH}) \mathrm{S}$ was and doped by a little Co in NF-C/Ni(OH)S (Figs. S13-S16). However, there were fewer nanosheets structure and no core-shell heterostructure in $\mathrm{NF}-\mathrm{C} / \mathrm{Ni}(\mathrm{OH}) \mathrm{S}$ compared with $\mathrm{NF}-\mathrm{C} / \mathrm{CoS} /$ $\mathrm{NiOOH}$.

The self-supporting electrocatalysts based on NF prepared by the Joule-heating and water soaking treatment could be 


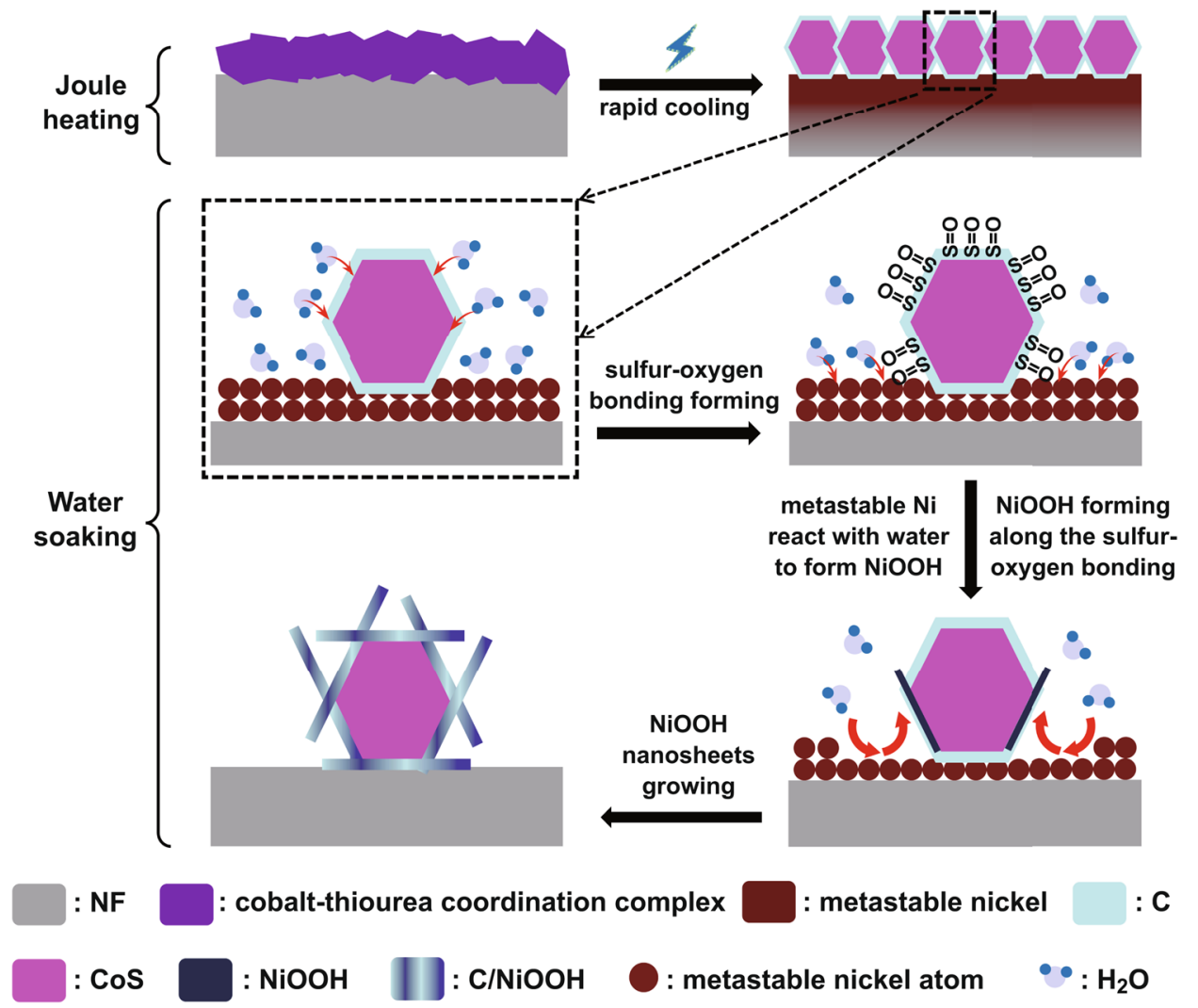

Fig. 4 Schematic diagram of the formation mechanism of NF-C/CoS/NiOOH

directly applied to measure the electrochemical performance of OER and HER. The electrochemical performances of OER were evaluated in a three-electrode cell by linear sweep voltammetry (LSV) shown in Fig. 5a. NF-C/CoS/NiOOH exhibited good OER performance with a low overpotential of $296 \mathrm{mV}$ at $10 \mathrm{~mA} \mathrm{~cm}{ }^{-2}$ compared with bare $\mathrm{NF}(442 \mathrm{mV})$ and NF-C/Ni(OH)S (319 mV). In addition, NF-C/CoS/ $\mathrm{NiOOH}$ showed good OER performance with a low overpotential of $361 \mathrm{mV}$ at high current density $\left(100 \mathrm{~mA} \mathrm{~cm}^{-2}\right)$ indicating superior reaction thermodynamics compared with $\mathrm{NF}-\mathrm{C} / \mathrm{Ni}(\mathrm{OH}) \mathrm{S}(449 \mathrm{mV})$. The electrocatalysts based on NF exhibited a semicircle intersecting with the $\mathrm{X}$-axis of Nyquist plots corresponding to the charge transfer resistance $\left(R_{\mathrm{ct}}\right)$ and solution resistance $\left(R_{\mathrm{s}}\right)$, respectively. The $R_{\mathrm{s}}$ related to the impedance of electrolyte depending on Nyquist plots intersection with the $\mathrm{X}$-axis, and the $R_{\mathrm{ct}}$ related to the current exchange defined by the Butler-Volmer equation depending on the arc diameter of semicircles on Nyquist plots reflecting the intrinsic resistance of electrocatalysts [27]. NF-C/CoS/ $\mathrm{NiOOH}$ possessed the smallest $R_{\mathrm{ct}}$ of $3.5 \Omega$ showing a low electronic transport barrier in contrast with bare NF (105.0 $\Omega$ ) and NF-C/Ni(OH)S (14.0 $\Omega$ ) (Fig. S17a). Moreover, the smaller Tafel slope of NF-C/CoS/NiOOH (52.9 mV dec $\left.{ }^{-1}\right)$ than bare NF (137.07 $\left.\mathrm{dec}^{-1}\right)$ and NF-C/Ni(OH)S (111.46 $\mathrm{dec}^{-1}$ ) indicated its superior OER reaction kinetics and high charge transfer coefficient (Fig. 5b). The ECSA investigated by double-layer capacitance $\left(C_{\mathrm{dl}}\right)$ showed that the $C_{\mathrm{dl}}$ of NF-C/CoS/NiOOH $\left(198.1 \mathrm{mF} \mathrm{cm}^{-2}\right)$ was higher than $\mathrm{NF}-\mathrm{C} / \mathrm{Ni}(\mathrm{OH}) \mathrm{S}\left(8.5 \mathrm{mF} \mathrm{cm}^{-2}\right)$ suggesting higher density of catalytical active sites on OER (Figs. $5 \mathrm{c}$ and S18a, b). Figure S19a shows the chronopotentiometry curve of NF-C/CoS/ $\mathrm{NiOOH}$ on OER indicating great stability of OER with an increase of $12 \mathrm{mV}$ after $40,000 \mathrm{~s}$. It was the high activity of $\mathrm{NiOOH}$ nanosheets and core-shell heterostructure of $\mathrm{C} / \mathrm{CoS} /$ $\mathrm{NiOOH}$ that led to the great OER performance of NF-C/ $\mathrm{CoS} / \mathrm{NiOOH}$. Meanwhile, N-, O-, S-doped carbon provides catalytic active sites and fast electron transfer route to some extent. The nanosheets of $\mathrm{NiOOH}$ induced and braced by $\mathrm{CoS}$ nanoparticles on NF-C/CoS/NiOOH could provide more active site for OER compared with $\mathrm{NF}-\mathrm{C} / \mathrm{Ni}(\mathrm{OH}) \mathrm{S}$ 

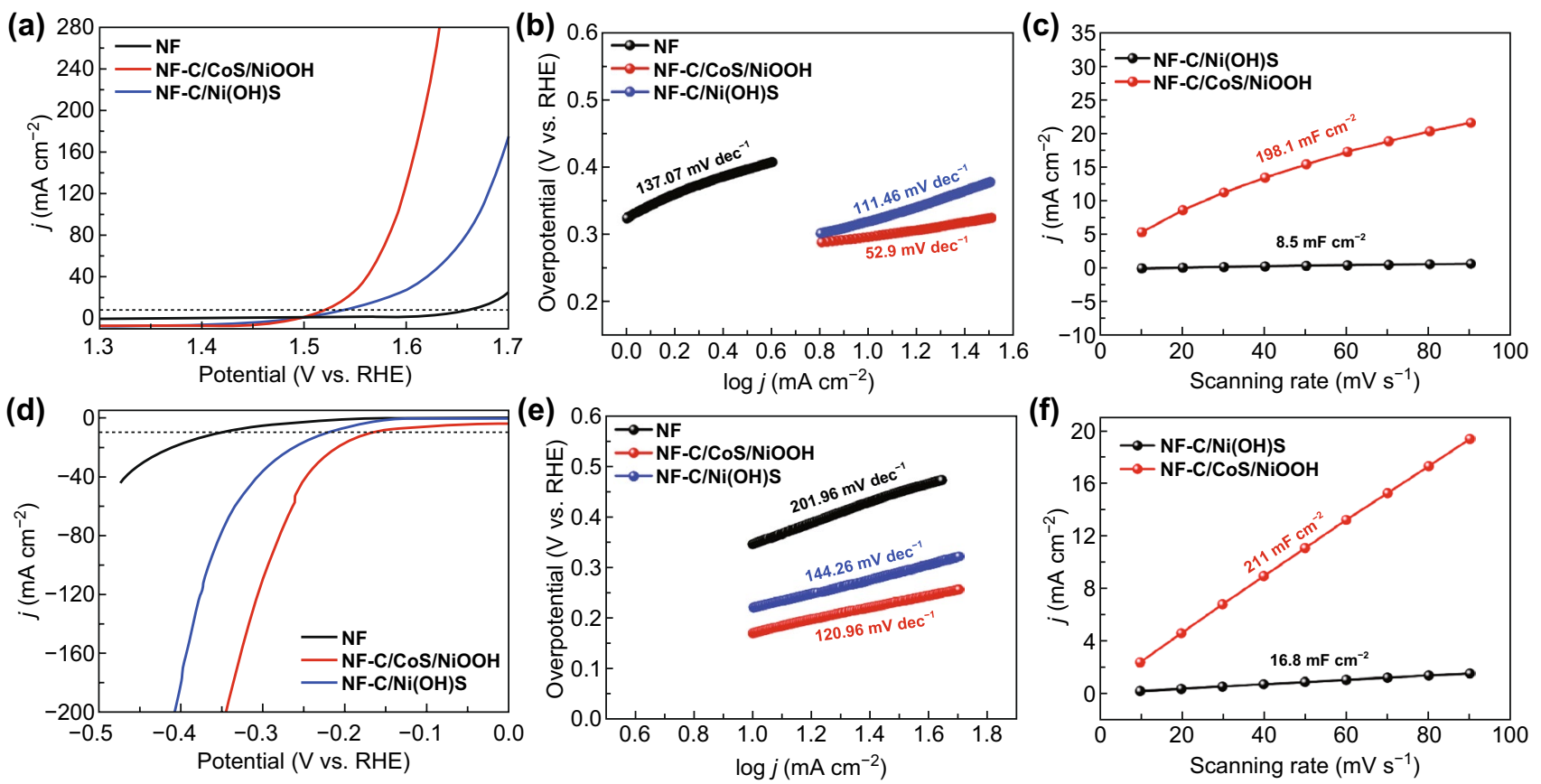

Fig. 5 a Polarization curves and $\mathbf{b}$ Tafel slopes of OER on bare NF, NF-C/CoS/NiOOH, and NF-C/Ni(OH)S. c $C_{\mathrm{dl}}$ of OER on NF-C/CoS/ $\mathrm{NiOOH}$ and NF-C/Ni(OH)S. d Polarization curves and e Tafel slopes of HER on bare NF, NF-C/CoS/NiOOH, and NF-C/Ni(OH)S. f $C_{\mathrm{dl}}$ of HER on NF-C/CoS/NiOOH and NF-C/Ni(OH)S

in which the $\mathrm{C} / \mathrm{Ni}(\mathrm{OH}) \mathrm{S}$ nanosheets were only on the surface of NF. In addition, the synergy of $\mathrm{NiOOH}$ and $\mathrm{CoS}$ core-shell heterostructure could improve the OER activity compared with the homogeneous phase of $\mathrm{C} / \mathrm{Ni}(\mathrm{OH}) \mathrm{S}$.

The electrochemical performances of HER were evaluated in a three-electrode cell by LSV shown in Fig. 5d. NF-C/ $\mathrm{CoS} / \mathrm{NiOOH}$ exhibited good HER performance with a low overpotential of $170 \mathrm{mV}$ at $10 \mathrm{~mA} \mathrm{~cm}{ }^{-2}$ compared with bare $\mathrm{NF}(347 \mathrm{mV})$ and $\mathrm{NF}-\mathrm{C} / \mathrm{Ni}(\mathrm{OH}) \mathrm{S}(221 \mathrm{mV})$ which was similar as the measurement of OER. Moreover, NF-C/CoS/ $\mathrm{NiOOH}$ showed good HER performance with a low overpotential of $294 \mathrm{mV}$ at high current density $\left(100 \mathrm{~mA} \mathrm{~cm}^{-2}\right)$ compared with NF-C/Ni(OH)S (365 mV). NF-C/CoS/ $\mathrm{NiOOH}$ also showed the smallest $R_{\mathrm{ct}}$ of $12.3 \Omega$ similar to the EIS result of OER compared with bare NF (105 $\Omega$ ) and $\mathrm{NF}-\mathrm{C} / \mathrm{Ni}(\mathrm{OH}) \mathrm{S}(14.9 \Omega)$ demonstrating faster electronic transport on HER measurement (Fig. S17b). The smallest Tafel slope of $120.96 \mathrm{mV} \mathrm{dec}^{-1}$ was shown on NF-C/ $\mathrm{CoS} / \mathrm{NiOOH}$ indicating its superior HER reaction kinetics and high charge transfer coefficient in contrast with bare $\mathrm{NF}\left(201.96 \mathrm{mV} \mathrm{dec}{ }^{-1}\right)$ and NF-C/Ni(OH)S (144.26 mV $\left.\mathrm{dec}^{-1}\right)$ in Fig. 5e. Higher $C_{\mathrm{dl}}$ of NF-C/CoS/NiOOH (211.0 $\left.\mathrm{mF} \mathrm{cm}^{-2}\right)$ than $\mathrm{NF}-\mathrm{C} / \mathrm{Ni}(\mathrm{OH}) \mathrm{S}\left(16.8 \mathrm{mF} \mathrm{cm}^{-2}\right)$ indicating its higher density of catalytical active sites on HER (Figs. $5 \mathrm{f}$ and S18c, d). Figure S19b shows the chronopotentiometry curve of NF-C/CoS/NiOOH on HER that the overpotential of HER was $184 \mathrm{mV}$ after 40,000 s. Similar to the test result of OER, NF-C/CoS/NiOOH showed better HER performance than bare NF and NF-C/Ni(OH)S because of the high activity of $\mathrm{NiOOH}$ nanosheets and core-shell heterostructure of $\mathrm{C} / \mathrm{CoS} / \mathrm{NiOOH}$. The nanosheets structure of NF-C/CoS/NiOOH can maintained after OER and HER (Figs. S21-S25). NF-C/CoS/NiOOH exhibited $\mathrm{CoOOH}$ nanosheets and $\mathrm{NiOOH}$ nanosheets after OER. NF-C/ $\mathrm{CoS} / \mathrm{NiOOH}$ exhibited $\mathrm{S}$-doped $\mathrm{Co}(\mathrm{OH})_{2}$ nanosheets and $\mathrm{Ni}(\mathrm{OH})_{2}$ nanosheets.

SEM, EDS, element distribution, and XPS were used to characterize NF-C/CoS/NiOOH after OER test and HER test for $10 \mathrm{~h}$ (Figs. S20-S24). NF-C/CoS/NiOOH exhibited $\mathrm{CoOOH}$ nanosheets and $\mathrm{NiOOH}$ nanosheets after OER. NF-C/CoS/NiOOH exhibited sulfur-doped $\mathrm{Co}(\mathrm{OH})_{2}$ nanosheets and $\mathrm{Ni}(\mathrm{OH})_{2}$ nanosheets. The carbon doped by $\mathrm{N}, \mathrm{S}, \mathrm{O}$ still exists on nanosheets.

In general, there are three reasons why NF-C/CoS/NiOOH showed good electrocatalytic performance. Firstly, there were more $\mathrm{NiOOH}$ nanosheets in $\mathrm{NF}-\mathrm{C} / \mathrm{CoS} / \mathrm{NiOOH}$ duo 
to the induction of $\mathrm{CoS}$ compared with $\mathrm{Ni}(\mathrm{OH}) \mathrm{S}$ nanosheets in $\mathrm{NF}-\mathrm{C} / \mathrm{Ni}(\mathrm{OH}) \mathrm{S}$. More nanosheets structure can provide more electrocatalytic sites, which can be proved in Fig. 5c, f. Secondly, Studies showed that $\mathrm{NiOOH}$ and sulfide forming core-shell structure or heterostructure can provide high OER and HER electrocatalytic activity due to the special structure and synergistic effect of $\mathrm{NiOOH}$ and sulfide. After continuous OER and HER test, CoS gradually transformed into $\mathrm{CoOOH}$ nanosheets and S-doped $\mathrm{Co}(\mathrm{OH})_{2}$ nanosheets, respectively, which still can provide high electrocatalysis activity. Finally, there are much carbon doped by N, O, S in $\mathrm{NF}-\mathrm{C} / \mathrm{CoS} / \mathrm{NiOOH}$ and $\mathrm{NF}-\mathrm{C} / \mathrm{Ni}(\mathrm{OH}) \mathrm{S}$ due to the pyrolysis reaction of cobalt-thiourea coordination complex and thiourea. The carbon doped by N, O, S can provide electrocatalysis activity.

As shown in Fig. S25, the Faraday efficiency results of OER on NF-C/CoS/NiOOH were $93.8 \%\left(10 \mathrm{~mA} \mathrm{~cm}^{-2}\right)$, 97.5\% $\left(20 \mathrm{~mA} \mathrm{~cm}^{-2}\right)$, and $99.1 \%\left(50 \mathrm{~mA} \mathrm{~cm}^{-2}\right)$. The Faraday efficiency results of HER on NF-C/CoS/NiOOH were 95.9\% (10 mA cm$\left.{ }^{-2}\right), 98.9 \%\left(20 \mathrm{~mA} \mathrm{~cm}^{-2}\right)$, and $99.2 \%$ $\left(50 \mathrm{~mA} \mathrm{~cm}^{-2}\right)$. In general, NF-C/CoS/NiOOH exhibited high Faraday efficiency at each current density. The Faraday efficiency at high current density is slightly higher than that at low current density because a small part of the current contributes to the pseudocapacitance at low current density.

As shown in Fig. S26a, NF-C/CoS/NiOOH exhibited a good overall water splitting performance with a lower cell voltage of $1.71 \mathrm{~V}$ than bare $\mathrm{NF}(2.04 \mathrm{~V})$ and $\mathrm{NF}-\mathrm{C} / \mathrm{Ni}(\mathrm{OH})$ $\mathrm{S}(1.81 \mathrm{~V})$ at a current density of $10 \mathrm{~mA} \mathrm{~cm}^{-2}$. Even though the NF-Pt/C//NF-IrO ${ }_{2}$ showed more excellent overall water splitting performance $(1.59 \mathrm{~V})$ than $\mathrm{NF}-\mathrm{C} / \mathrm{CoS} / \mathrm{NiOOH}$ $(1.71 \mathrm{~V})$ at $10 \mathrm{~mA} \mathrm{~cm}{ }^{-2}, \mathrm{NF}-\mathrm{C} / \mathrm{CoS} / \mathrm{NiOOH}$ exhibited low overall water splitting overpotential $(1.96 \mathrm{~V})$ than NF$\mathrm{Pt} / \mathrm{C} / / \mathrm{NF}-\mathrm{IrO}_{2}(1.97 \mathrm{~V})$ at $200 \mathrm{~mA} \mathrm{~cm}^{-2}$ indicating the great overall water splitting performance at high current density. NF-C/CoS/NiOOH showed smaller $R_{\mathrm{ct}}(11.2 \Omega)$ than bare $\mathrm{NF}(278.1 \Omega)$ and NF-C/Ni(OH)S (32.9 $\Omega$ ) which was similar to the EIS test results of OER and HER (Fig. S26b). Figure S26c shows the chronopotentiometry curve of NF-C/ $\mathrm{CoS} / \mathrm{NiOOH}$ on overall water splitting test indicating good stability with the increase of $74 \mathrm{mV}$ after $50,000 \mathrm{~s}$. Figure S26d shows the demonstration of overall water splitting on $\mathrm{NF}-\mathrm{C} / \mathrm{CoS} / \mathrm{NiOOH}$ with obvious bubbles generation.

\section{Conclusions}

In summary, we reported a Joule-heating method and water soaking treatment to synthesis the nanomaterials based on $\mathrm{NF}$ as self-supporting electrocatalysts fast and simply for overall water splitting. The cobalt-thiourea coordination complex on NF converted to carbon-coated $\mathrm{CoS}$ on NF by Joule-heating that the carbon was N-, O-, S-doped carbon and a small amount of Ni was doped into CoS. Notably, the nickel on the surface of NF activated by Joule-heating and cobalt-thiourea coordination complex led to the spontaneous growing of $\mathrm{NiOOH}$ nanosheets in water induced by $\mathrm{CoS}$ so that NF-C/CoS/NiOOH with hierarchical nanosheets structure and core-shell heterostructure was prepared. We speculated that the driving force of nanosheets structure generation was the metastable nickel and $\mathrm{CoS}$ could induce the $\mathrm{NiOOH}$ nanosheets growing continually. NF-C/CoS/NiOOH as a self-supporting electrocatalyst exhibited good performance of OER, HER, and overall water splitting. Our work provided a new route to synthesize nanomaterials based on NF that offered a new developing direction in the catalysis and energy field compared with traditional synthesis methods.

Acknowledgements This work was supported by the National Natural Science Foundation of China (Nos. 91963113, 51701139, and U1601216).

Open Access This article is licensed under a Creative Commons Attribution 4.0 International License, which permits use, sharing, adaptation, distribution and reproduction in any medium or format, as long as you give appropriate credit to the original author(s) and the source, provide a link to the Creative Commons licence, and indicate if changes were made. The images or other third party material in this article are included in the article's Creative Commons licence, unless indicated otherwise in a credit line to the material. If material is not included in the article's Creative Commons licence and your intended use is not permitted by statutory regulation or exceeds the permitted use, you will need to obtain permission directly from the copyright holder. To view a copy of this licence, visit http://creativecommons.org/licenses/by/4.0/.

Electronic supplementary material The online version of this article (https://doi.org/10.1007/s40820-020-00505-2) contains supplementary material, which is available to authorized users. 


\section{References}

1. D. Larcher, J.M. Tarascon, Towards greener and more sustainable batteries for electrical energy storage. Nat. Chem. 7(1), 19-29 (2015). https://doi.org/10.1038/nchem.2085

2. S. Chu, AJn Majumdar, Opportunities and challenges for a sustainable energy future. Nature 488(7411), 294-303 (2012). https://doi.org/10.1038/nature11475

3. Y. Yan, B.Y. Xia, B. Zhao, X. Wang, A review on noblemetal-free bifunctional heterogeneous catalysts for overall electrochemical water splitting. J. Mater. Chem A 4(45), 17587-17603 (2016). https://doi.org/10.1039/c6ta08075h

4. L. Huang, D. Chen, G. Luo, Y.R. Lu, C. Chen et al., Zirconium-regulation-induced bifunctionality in $3 \mathrm{~d}$ cobalt-iron oxide nanosheets for overall water splitting. Adv. Mater. 31(28), e1901439 (2019). https://doi.org/10.1002/adma.20190 1439

5. H. Sun, Z. Yan, F. Liu, W. Xu, F. Cheng, J. Chen, Self-supported transition-metal-based electrocatalysts for hydrogen and oxygen evolution. Adv. Mater. 32(3), e1806326 (2020). https://doi.org/10.1002/adma.201806326

6. Y. Li, Y. Sun, Y. Qin, W. Zhang, L. Wang et al., Recent advances on water-splitting electrocatalysis mediated by noble-metal-based nanostructured materials. Adv. Energy Mater. 10(11), 1903120 (2020). https://doi.org/10.1002/ aenm. 201903120

7. Y. Yan, B.Y. Xia, B. Zhao, X. Wang, A review on noblemetal-free bifunctional heterogeneous catalysts for overall electrochemical water splitting. J. Mater. Chem. A 4, 17587 (2016). https://doi.org/10.1039/c6ta08075h

8. X. Shi, J. Key, S. Ji, V. Linkov, F. Liu et al., Ni(OH) $)_{2}$ nanoflakes supported on $3 \mathrm{~d} \mathrm{Ni}_{3} \mathrm{Se}_{2}$ nanowire array as highly efficient electrodes for asymmetric supercapacitor and $\mathrm{Ni} /$ Mh battery. Small 15(29), e1802861 (2019). https://doi. org/10.1002/smll.201802861

9. Y. Zhao, X. Liu, X. Wang, P. Zhang, J. Shi, Peony petallike $3 \mathrm{~d}$ graphene-nickel oxide nanocomposite decorated nickel foam as high-performance electrocatalyst for direct glucose alkaline fuel cell. Int. J. Hydrogen Energ. 42(50), 29863-29873 (2017). https://doi.org/10.1016/j.ijhyd ene.2017.10.120

10. Z. Xue, X. Li, Q. Liu, M. Cai, K. Liu et al., Interfacial electronic structure modulation of NiTe nanoarrays with NiS nanodots facilitates electrocatalytic oxygen evolution. Adv. Mater. 31(21), e1900430 (2019). https://doi.org/10.1002/adma.20190 0430

11. Q. Qian, Y. Li, Y. Liu, L. Yu, G. Zhang, Ambient fast synthesis and active sites deciphering of hierarchical foam-like trimetal-organic framework nanostructures as a platform for highly efficient oxygen evolution electrocatalysis. Adv. Mater. 31(23), e1901139 (2019). https://doi.org/10.1002/adma.20190 1139
12. H. Xu, B. Fei, G. Cai, Y. Ha, J. Liu et al., Boronizationinduced ultrathin $2 \mathrm{~d}$ nanosheets with abundant crystallineamorphous phase boundary supported on nickel foam toward efficient water splitting. Adv. Energy Mater. 10(3), 1902714 (2020). https://doi.org/10.1002/aenm.201902714

13. S. Liu, Y. Jiang, M. Yang, M. Zhang, Q. Guo et al., Highly conductive and metallic cobalt-nickel selenide nanorods supported on $\mathrm{Ni}$ foam as an efficient electrocatalyst for alkaline water splitting. Nanoscale 11(16), 7959-7966 (2019). https:// doi.org/10.1039/c8nr10545f

14. Y. Chen, G.C. Egan, J. Wan, S. Zhu, R.J. Jacob et al., Ultrafast self-assembly and stabilization of reactive nanoparticles in reduced graphene oxide films. Nat. Commun. 7, 12332 (2016). https://doi.org/10.1038/ncomms12332

15. Y.G. Yao, Z.N. Huang, P.F. Xie, S.D. Lacey, R.J. Jacob et al., Carbothermal shock synthesis of high-entropy-alloy nanoparticles. Science 359(6383), 1489-1494 (2018). https://doi. org/10.1126/science.aan5412

16. Y. Yao, Z. Huang, P. Xie, L. Wu, L. Ma et al., High temperature shockwave stabilized single atoms. Nat. Nanotechnol. 14(9), 851-857 (2019). https://doi.org/10.1038/s4156 5-019-0518-7

17. Y.N. Chen, S.M. Xu, Y.C. Li, R.J. Jacob, Y.D. Kuang et al., $\mathrm{FeS}_{2}$ nanoparticles embedded in reduced graphene oxide toward robust, high-performance electrocatalysts. Adv. Energy Mater. 7(19), 1700482 (2017). https://doi.org/10.1002/ aenm.201700482

18. S.M.S. Kumar, K. Selvakumar, R. Thangamuthu, One-pot hydrothermal synthesis of supported cos electrocatalysts: the effect of support nature on oxygen reduction reaction activity in alkaline medium. Int. J. Hydrogen Energ. 43(9), 4773-4783 (2018). https://doi.org/10.1016/j.ijhydene.2017.12.063

19. J. Zhou, Y. Dou, A. Zhou, R.M. Guo, M.J. Zhao, J.R. Li, MOF template-directed fabrication of hierarchically structured electrocatalysts for efficient oxygen evolution reaction. Adv. Energy Mater. 7(12), 1602643 (2017). https://doi.org/10.1002/ aenm.201602643

20. W. Yu, H. Wang, S. Liu, N. Mao, X. Liu et al., N, O-co doped hierarchical porous carbons derived from algae for highcapacity supercapacitors and battery anodes. J. Mater. Chem. A 4(16), 5973-5983 (2016). https://doi.org/10.1039/c6ta0 $1821 \mathrm{a}$

21. X. Li, B.Y. Guan, S. Gao, X.W. Lou, A general dual-templating approach to biomass-derived hierarchically porous heteroatom-doped carbon materials for enhanced electrocatalytic oxygen reduction. Energ. Environ. Sci. 12(2), 648-655 (2019). https://doi.org/10.1039/c8ee02779j

22. H.-Y. Wang, Y.-Y. Hsu, R. Chen, T.-S. Chan, H.M. Chen, B. $\mathrm{Liu}, \mathrm{Ni}^{3+}$-induced formation of active $\mathrm{NiOOH}$ on the spinel Ni-Co oxide surface for efficient oxygen evolution reaction. Adv. Energy Mater. 5(10), 1500091 (2015). https://doi. org/10.1002/aenm.201500091 
23. Z. Xiao, G. Xiao, M. Shi, Y. Zhu, Homogeneously dispersed $\mathrm{Co}_{9} \mathrm{~S}_{8}$ anchored on nitrogen and sulfur co-doped carbon derived from soybean as bifunctional oxygen electrocatalysts and supercapacitors. ACS Appl. Mater. Interfaces. 10(19), 16436-16448 (2018). https://doi.org/10.1021/acsami.8b01592

24. Y. Chen, S. Xu, S. Zhu, R.J. Jacob, G. Pastel et al., Millisecond synthesis of cos nanoparticles for highly efficient overall water splitting. Nano Res. 12(9), 2259-2267 (2019). https:// doi.org/10.1007/s12274-019-2304-0

25. X. Zheng, Y. Cao, X. Han, H. Liu, J. Wang et al., Pt embedded $\mathrm{Ni}_{3} \mathrm{Se}_{2} @ \mathrm{NiOOH}$ core-shell dendrite-like nanoarrays on nickel as bifunctional electrocatalysts for overall water splitting. Sci. China Mater. 62(8), 1096-1104 (2019). https://doi. org/10.1007/s40843-019-9413-5
26. T. Liu, D.D. Han, L. Wang, G.R. Li, S. Liu, X.P. Gao, $\mathrm{NiCo}_{2} \mathrm{O}_{4}$ nanofibers as carbon-free sulfur immobilizer to fabricate sulfur-based composite with high volumetric capacity for lithium-sulfur battery. Adv. Energy Mater. 9(11), 1803477 (2019). https://doi.org/10.1002/aenm.201803477

27. D.P. Dubal, G.S. Gund, C.D. Lokhande, R. Holze, Decoration of spongelike $\mathrm{Ni}(\mathrm{OH})_{2}$ nanoparticles onto mwcnts using an easily manipulated chemical protocol for supercapacitors. ACS Appl. Mater. Interfaces 5(7), 2446-2454 (2013). https:// doi.org/10.1021/am3026486 